\section{CALENDAR OF RECENT AND FORTHCOMING CONFERENCES}

\section{World Massage Conference}

November 17-22, 2008; World Massage Conference Website Classroom

This virtual conference used the power of the web to bring together more than 50 of the world's top massage experts over a 6-day period. Recorded replays of all presentations-replete with online notes or slideshows - are available until May 31, 2009.

For further information regarding registration for access to the recorded replays, please visit http:// www.worldmassageconference.com/.

\section{Training Researchers in Manual Medicine} March 23 - 24, 2009; The Peabody Hotel, Little Rock, AR, U.S.A.

For detailed information, please visit http:// www.hsc.unt.edu/orc/events.htm.

\section{Hand in Hand Symposium 2009}

May 1-3, 2009; Caribe Royal, Orlando, FL, U.S.A.

For detailed information, please visit http:// www.handinhand2009.com.

\section{CAHCIM North American Research Conference on Complementary and Integrative Medicine*} May 12 - 15, 2009; Hilton Minneapolis, Minneapolis, $M N$, U.S.A.

The Consortium of Academic Health Centers in Integrative Medicine (CAHCIM) announces its 2009 North American Research Conference on Complementary and Integrative Medicine. For further details on the 2009 conference, please visit http:// www.imconsortium-conference.org/info/ call abstracts.php.

\section{SpiritHeals Integrative Medicine Conference} May 19-31, 2009; Victoria, BC, Canada

For detailed information, please visit http:// www.spiritheals.ca/.

\section{AMTA National Convention}

September 23-26, 2009; Rosen Shingle Creek Resort, Orlando, FL, U.S.A.

For detailed information, please visit http:// www.amtamassage.org.

\author{
Second International Fascia Research \\ Congress* \\ October 27-30, 2009; Amsterdam, Netherlands
}

The conference covers recent basic and applied research and reviews in soft connective tissue sciences at all levels - molecular, cellular, tissue, organ, compartment, and limb or trunk and whole body - and in all disciplines - for example, molecular biology, cytology, histology, anatomy, physiology, biochemistry, biomechanics, neurology, surgery. It will include (a) free oral and poster presentations of peer-reviewed research; (b) special panels and presentations that will address the research interests of clinical practitioners in acupuncture, chiropractic, massage, neuromuscular therapies, osteopathy, physiatry, physical therapy, sports medicine, structural bodywork, and surgery; (c) demonstrations of clinical practice techniques at both podium and small-group sessions aimed at bringing manual therapy clinicians and scientists together to enhance common research interests and communication. There will be an opportunity to attend several postcongress workshops on Saturday, October 31, 2009, at Vrije Universiteit, Amsterdam. These workshops will provide a forum for clinical practitioners to present their methodologies and research questions so as to crosseducate other clinicians and stimulate new areas of inquiry by research scientists.

Call for abstracts: submission deadline, February 15,2009

For complete information, online registration, and paper submission, please visit http://www.fasciacongress.org.

\section{9th Annual Integrated Care Conference November 3-6, 2009; Vienna, Austria}

The 9th Annual Integrated Care Conference is titled Lost in Transition: Meeting the Challenge through Integrated Care.

For detailed information, please visit http:// www.integratedcare.eu/inic09vienna/index.html.

Highlighting Massage Therapy in CIM Research May $13-15,2010$

The Massage Therapy Foundation is pleased to present the second Highlighting Massage Therapy in CIM [Complementary and Integrative Medicine] Research conference (see the "Save the Date" conference reminder at http://www.massagetherapyfoundation.org/ pdf/STD 2010.pdf). This 3-day conference brings together massage and manual therapy practitioners, educators, CIM researchers, allied health professionals, and others interested in massage research. Current research and manual therapy-related research will be presented, with a special focus on translational research and public health. 
A call for papers will be issued shortly, and registration is scheduled to open in late 2009. For more information, please contact Alison Pittas at apittas@massagetherapyfoundation.org.

\section{5th International Congress on Complementary and Alternative Medicine Research}

May 19-21, 2010; Tromsø, Norway

For detailed information, please visit http:// www.iccmr2010.com or contact Vinjar Fønnebø at Vinjar.Fønnebø@,fagmed.uit.no.

\section{NCCAM/NIH NEWS AND GRANT APPLICATION ANNOUNCEMENTS}

\section{New CAM Research Centers}

NCCAM (National Center for Complementary and Alternative Medicine) has added four new Centers of Excellence for Research on Complementary and Alternative Medicine to its research centers program. The new centers will add to knowledge about CAM approaches and their potential in treating and preventing diseases and conditions that are common among Americans. Visit http://nccam.nih.gov/news/2008/102008.htm.

\section{New Statistics on CAM Use}

Approximately $38 \%$ of adults in the United States aged 18 years and over, and nearly $12 \%$ of U.S. children aged 17 years and under, use some form of CAM, according to the 2007 National Health Interview survey released last week. This survey marks the first time questions were included on children's use of CAM. Visit http://nccam.nih.gov/news/camstats.htm.

\section{NCCAM-Funded Research for Fiscal Year 2008}

A list of research and training grants funded with both new and ongoing research funding by NCCAM (National Center for Complementary and Alternative Medicine) during fiscal year 2007 has been released. The list includes grant number, project title, principal investigator, institution, and state. Visit http:/ /nccam.nih.gov/research/extramural/awards/2008/.

\section{NCCAM Celebrates 10th Anniversary}

The year 2009 marks 10 years since NCCAM (National Center for Complementary and Alternative Medicine) was established by Congress. The agency will be celebrating 10 years of rigorous research with a series of events and materials. Visit http:// nccam.nih.gov/news/2009/anniversary.htm.
RFA-AT-09-002

Translational Tools for Clinical Studies of CAM Interventions (R01)

Program number: 01788

Sponsor: National Center for Complementary and Alternative Medicine

Synopsis: The sponsor invites applications that propose to develop, enhance, and validate translational tools to facilitate rigorous study of complementary and alternative medicine (CAM) approaches that are in wide use by the public. CAM approaches being widely used include massage and manipulative therapies, meditation, yoga, and acupuncture. Health conditions, particularly chronic pain, back pain, and musculoskeletal pain, are the most commonly cited reasons for their use. This Funding Opportunity Announcement (FOA) focuses on encouraging the development of improved research methodology to study safety, efficacy, and clinical effectiveness of widely used CAM approaches, such as mind-body interventions, manual therapies, yoga, and acupuncture. This FOA will use the NIH Research Project (R01) award mechanism.

Contact: Dr. Partap S. Khalsa

E-mail: khalsap@mail.nih.gov

Program URL: http://grants1.nih.gov/grants/guide/ rfa-files/RFA-AT-09-002.html

Tel: $301-594-3462$

Fax: 301-480-1587

Deadline note: Applications may be submitted to http://Grants.gov in response to this announcement on or after June 17, 2009. The deadline for receipt of full applications is July 17, 2009.

RFA-AT-09-003

Tools and Technologies for Assessing Manual Therapies (SBIR [R43/R44]) Grant

Sponsor: National Institutes of Health

Purpose: This Funding Opportunity Announcement (FOA) solicits Small Business Innovation Research (SBIR) grant applications from small business concerns (SBCs) that propose to develop new or innovative uses of existing technology, or develop new technology, research tools, instruments, or devices to 1) illuminate the mechanisms of action of the biological effects of manual therapies; 2) facilitate quantitative assessment of the local and systemic effects of manual therapies.

Mechanism of Support: This FOA will use the SBIR (R43/R44) grant mechanisms for Phase I, Phase II, and Fast-Track applications.

Funds Available and Anticipated Number of Awards: The estimated amount of funds available for support of $3-5$ projects awarded as a result of this announcement is $\$ 1$ million for fiscal year 2009. Future-year amounts will depend on annual appropriations.

Current Closing Date for Applications: June 1, 2009 
Synopsis Link: http://www07.grants.gov/search/ search.do?\&mode=VIEW\&flag2006=-false\&oppId $=45371$ Full Announcement Link: http://grants.nih.gov/ grants/guide/rfa-files/RFA-AT-09-003.html

\section{Basic and Preclinical Research on Complementary and Alternative Medicine (CAM) (R01)}

Program number: 88339

Sponsor: National Center for Complementary and Alternative Medicine/NIH/DHHS

Synopsis: The sponsors offer support for basic or preclinical research on CAM areas of special interest with an aim to understand the mechanisms of action of a CAM modality. This program will use the NIH Research Project Grant (R01) award mechanism.

Contact: Carol Pontzer, PhD

E-mail: pontzerc@mail.nih.gov

Program URL: http://grants1.nih.gov/grants/guide/ pa-files/PA-09-010.html

Tel: $301-435-6286$

Fax: 301-480-3621

Deadline note: Applications may be submitted to http://Grants.gov in response to this announcement on or after January 5, 2009. The deadlines for receipt of standard R01 applications under this announcement are February 5, June 5, and October 5 annually. The deadlines for receipt of AIDS-related applications are January 7, May 7, and September 7 annually. This program will expire on January 8, 2012. Electronic application submission is required for this Funding Opportunity Announcement.

\section{Biology of Manual Therapies (R21)}

Program number: 87574

Sponsor: National Center for Complementary and Alternative Medicine/NIH/DHHS

Synopsis: The sponsors offer support for studies of the basic science and mechanisms of action underlying the biomechanical, immunologic, endocrinologic, or neurophysiologic consequences of manual therapies, such as spinal manipulation, mobilization, and massage therapy. This program will use the NIH Exploratory/Developmental (R21) grant mechanism.

Contact: Partap Khalsa, DC, PhD, DABCO, Program Officer

E-mail: khalsap@mail.nih.gov

Program URL: http://grants 1.nih.gov/grants/guide/ pa-files/PAR-06-312.html

Tel: 301-594-3462
Fax: 301-401-1587

Deadline note: The deadlines for receipt of standard applications under this announcement are February 16, June 16, and October 16 annually. The deadlines for receipt of AIDS-related applications are January 7, May 7 , and September 7 annually. This program will expire on September 8, 2009.

\section{ADDITIONAL ANNOUNCEMENTS/REMINDERS}

\section{Launch of the Science of Massage Website and Its Affiliated Journal of Massage Science}

Ross Turchaninov, MD, and colleagues have recently launched the Science of Massage website (http:// www.scienceofmassage.com). Included among the several components of this interactive website is the bimonthly Journal of Massage Science that published its first issue in January 2009. Also included is an extensive instructional video library with entries relating to (a) therapeutic and stress-reduction massage and (b) medical massage protocols. Congratulations to Dr. Turchaninov and his team for these additional resources that serve to advance the scientific basis of the massage profession.

\section{Massage Therapy Foundation's Practitioner Case Report Contest}

The Massage Therapy Foundation invites participation in its Practitioner Case Report Contest. The Foundation has chosen to encourage the writing of case reports to provide an opportunity for massage therapists and bodyworkers to develop research skills and to enhance their ability to provide knowledgebased massage to the public. Please see the $\underline{2009}$ Practitioner Case Report Contest Guidelines for further information.

Submission deadline: October 8, 2009

\section{JBMT Accepted for Indexing in MEDLINE}

MEDLINE will start indexing entries in the Journal of Bodywork and Movement Therapies from the year of acceptance - that is, 2008 - beginning with issue 12(1). Backfiles extending to the year of the journal's inception, 1996, will also be available via PubMed. Congratulations to the JBMT's editor, Leon Chaitow, ND, DO, and colleagues for this milestone accomplishment.

* The Massage Therapy Foundation is co-sponsoring this event.

Executive Editor's Note: Colleagues are strongly encouraged to share information pertinent to this News/ Announcements section of the IJTMB. Please forward possible entries to the IJTMB 's Executive Editor at the following email address: hymel@loyno.edu. 